\title{
Progressive Damage and Failure Prediction of Open Hole Tension and Open Hole Compression Specimens
}

\author{
Ashith P. K. Joseph* and Anthony M. Waas ${ }^{\dagger}$ \\ University of Michigan, Ann Arbor, MI, 48109, USA. \\ Wooseok $\mathrm{Ji}^{\ddagger}$ \\ Ulsan National Institute of Science and Technology, Ulsan, S. Korea \\ Evan J. Pineda ${ }^{\S}$ \\ NASA Glenn Research Center, Cleveland, OH, 44113 \\ Salvatore Liguore and Steven Wanthal" \\ Boeing Research \&3 Technology, St. Louis, MO, 63166, USA.
}

\begin{abstract}
Progressive damage and failure in open hole composite laminate coupons under tensile and compressive loading conditions is modeled using Enhanced Schapery Theory (EST). The input parameters required for EST are obtained using standard coupon level test data and are interpreted in conjunction with finite element (FE) based simulations. The capability of EST to perform the open hole strength prediction accurately is demonstrated using three different layups of IM7/8552 carbon fiber composite. A homogenized approach uses a single composite shell element to represent the entire laminate in the thickness direction and this requires the fiber direction fracture toughness to be modeled as a laminate property. The results obtained using the EST method agree quite well with experimental results.
\end{abstract}

\section{Introduction}

The deformation response of laminated fiber reinforced composite panels with open holes can be used to assess modeling tools used in structural integrity and damage tolerance (SIDT) studies. Davidson et $\mathrm{al}^{1}$ presented a unified model for the open hole tension (OHT) and open hole compression (OHC) strength predictions using Enhanced Schapery Theory ${ }^{2}$ (EST). The EST model is used in the present study to determine the damage and failure evolution in open hole compression and tension specimens made of IM7/8552 material.

EST is proven to be an effective way of modeling the in-plane micro damage and failure evolution in composite laminates. Ability of this model to predict the strength of coupons with holes and notches under remote uniaxial loading conditions has been reported in the literature. ${ }^{2,1}$ In EST, the pre-peak non-linearity caused by micro damage in plies is modeled using polynomial functions which represent how the shear and transverse lamina moduli get affected by the development of micro damage in the polymer matrix. Upon reaching a critical limit in micro damage accumulation, the subsequent failure which is represented as a

\footnotetext{
*Graduate Student Research Assistant, Department of Aerospace Engineering, 2036 FXB

$\dagger$ Felix Pawlowski Collegiate Professor, Department of Aerospace Engineering, 3044 FXB, AIAA Fellow.

¥Assistant Professor, School of Mechanical and Nuclear Engineering, 301-3 1st Engr. Bldg., AIAA Member

$\S$ Aerospace Research Engineer, Mechanics and Life Prediction Branch, 21000 Brookpark Rd., MS 49-7, AIAA Member

I Technology Manager, Structures Technology, St. Louis, MO

$\|$ Technical Fellow, Boeing R \& T, St. Louis, MO.

${ }^{* *}$ Copyright@ 2015 , by Ashith Joseph, Anthony M. Waas, Wooseok Ji, Evan Pineda, Salvatore Liguore and Steven Wanthal. Published by the American Institute of Aeronautics and Astronautics, Inc., with permission.
} 
negative tangent to the slope of the stress-strain response (post peak region) is modeled using crack band theory. ${ }^{3}$ Details of the EST formulation can be found in Pineda and Waas, 2013. ${ }^{2}$

In this study, the composite laminate is modeled using shell elements and this ensures computational efficiency of the model. Previous studies with EST have considered fiber direction fracture toughness as a material property even when all the layers are modeled using a single shell element. In the present approach this property is calculated as a function of the composite layup according to an approach suggested by Camanho and Catalanotti. ${ }^{4}$ EST predictions are compared against open hole tension and open hole compression test data as well as with the test results published in NIAR test report ${ }^{5}$ for three different layups of IM7/8552 material.

\section{Finite Element Modeling}

Standard dimensions as per ASTM-D5766 is used for the finite element modeling of the open hole specimens. Dimensions and boundary conditions used for modeling are shown in figure 1. Out of plane degrees of freedom of all the nodes are restricted and the boundary conditions are applied on the left and right edges of the model. Nodes on the left edge are prevented from in-plane rotation and movement in $x$-direction, while prescribed displacement values in the $x$-direction and fixed in-plane rotation conditions are applied to the nodes on the right edge. EST is implemented as a user material subroutine (VUMAT) within the Abaqus/explicit solver and the in-plane failure of the laminate is modeled using 4-noded reduced integration shell elements (S4R). The same model is used for the open hole compression simulation with the remote loading direction being reversed. The failure/fracture properties used are dependent on the local stress state (tension vs. compression) and this aspect is incorporated in EST. Mesh sizes were determined based on a convergence study of the stress field near the hole and also by considering the element size restrictions imposed by the crack band model.

Three different layups are considered for this study and the layups are listed in table 1. Differences in the layer interfaces and the directional stiffness of the layups allows to test the applicability of the EST model and also understand it's limitations. The exact same mesh and modeling approach is used for all three layups and it was also found in the study that depending on the layup mesh refinement requirements could be different. The mesh chosen here gives a converged gradient stress field near the hole for all three layups.

\section{II.A. Input Parameters}

All input parameters required for EST are obtained using coupon level tests and in some cases, using inverse calculations using FE models of the coupon tests. Schapery microdamage functions are crucial for accurate modeling of pre-peak matrix non-linearity and these functions control the change in transverse and shear moduli as function of the micro cracks in the matrix. ${ }^{6,7} \pm 45$ tension tests are used to characterize the elastic damage response of the matrix according to the procedure give in $\mathrm{Ng}$ et al. ${ }^{8}$ While shear microdamage function is determined directly from the test data, tranverse microdamage function is calculated using a virtual test of the RUC with the matrix equivalent stress strain response backed out from the \pm 45 test data as an input. ${ }^{8}$ Microdamage functions are expressed as fifth order polynomials and table2 shows the coefficients of the polynomials calculated using the above mentioned method. Micro damage functions in compression are assumed to be same as that in tension for the analyses presented here.

Table3 summarizes the lamina strength and fracture input parameters used in the model. Virtual testing is used for calculating fiber direction compressive strength (due to kinking). Fiber misalignment angle of 1.2, which is the typical value found in industrial composites, ${ }^{9}$ is used in the compressive strength calculation done using micromechanics. Details of such a calculation are outlined in Davidson et al. ${ }^{1}$ Different longitudinal stuffness $\left(E_{11}\right)$ values are used in tension and compression as observed in the experiments and also reported in the literature. ${ }^{5}$

One of the critical factors in modeling the progressive failure using a crack band approach is estimating the correct fracture toughness values as they control the post peak softening behavior and hence the failure evolution. Fiber direction fracture toughness of the 0 layer can be obtained using a single edge notch tension (SENT) test/simulation, of the [90/0]s specimen as reported in Boyd et al. ${ }^{10}$ This value is then scaled for different layups as discussed in the following section, using the approach suggested by. ${ }^{4}$ For compressive loading, fiber direction overstress fracture toughness is not known and it is assumed to be about $25 \%$ of 
the value in tension. This assumption is further validated by comparing with the test results. Intralaminar mode I and mode II fracture toughness values are assumed to be the same as the corresponding interlaminar properties obtained from DCB and ENF tests. Matrix mode I fracture toughness in compression is assumed to be same as in tension.

\section{II.B. Fracture Toughness Corrections}

Composite shell elements ensure same in-plane strains for all the layers in the laminate and this in turn establishes the relative stresses in the layers as a function of the layup. Strain compatibility conditions between the layers add constraints to the model and this will lead to all the layers dissipating energy in the event of failure. But in reality this might not happen as delamination modes can dissipate energy and relax some layers. Hence using the fiber fracture toughness of the 0 layer for all the layers could be incorrect and will lead more energy dissipation than what is required depending on the laminate stacking. Camanho and Catalatonni ${ }^{4}$ developed a model to determine the fracture toughness of the laminate as a function of lamina fracture toughness. Fracture toughness of the i-th layer is calculated as a function of the material properties and 0 layer fracture toughness using Classical Lamination Theory and Linear Elastic Fracture Mechanics as given in the equation below.

$$
G_{c}^{i}=\frac{E_{e q}^{0}}{E_{e q}^{i}} \frac{\chi^{i^{2}}}{\chi^{0^{2}}} \Omega^{i^{2}} G_{c}^{0}
$$

Assuming self-similar crack growth in all layers, effective laminate fracture toughness is calculated as the weighted average of the toughness of the individual layers.

$$
G_{c}^{L}=\frac{\sum_{i} G_{c}^{i} t^{i}}{t^{L}}
$$

Laminate fracture toughness values calculated using equation 2 is given in table 3 . These values scale with the fraction of 0 layers present in the laminate. Thus, when the entire laminate is modeled as a single entity, the fracture toughness to be used will be different for different laminate stacking.

The second correction used in the fracture toughness values is with respect to the logarithmic strain used by Abaqus in Explicit simulations when the non-linear geometry option is turned on. This has been studied by Xu and Waas, ${ }^{11}$ and a schematic shown in figure 2 depicts the error which can arise due to this. A linear separation to crack strain conversion assumption used in the implementation of traction-separation law is only valid when the finite element computation uses engineering strain for the calculations. In order to overcome this, fracture energy is corrected by a factor as shown in equation 3, which is taken from Wu and Waas ${ }^{11}$

$$
G_{\text {corrected }}=\frac{\sigma_{c} l_{e}}{2} \ln \left(1+\frac{2 G_{c}}{\sigma_{c} l_{e}}\right)
$$

This ensures the correct correlation between the final crack separation in the traction-separation law with the VUMAT implementation in Abaqus. Errors arising due to this issue are problem dependent and if the final crack strain for the problem is considerably large or not. ${ }^{11}$

\section{II.C. Enahnced Schapery Theory and Implementation}

EST formulation combines Schapery theory with crack band approach to have the capability to model both the damage (pre-peak) and failure (post-peak) in composites. In EST, damage is defined as microcracks developing in the matrix under shear and transverse loading and at the lamina level this is seen as pre-peak non-linearity. While damage influences the transverse and shear moduli, longitudinal stiffness is not affected by it. Failure accounts for all the macroscopic cracks occurring in the lamina. These macroscopic cracks results in the post peak softening at the lamina level response and it is modeled using the crack band model of Bazant and Oh. ${ }^{3}$ Figure 3 shows the fundamental idea behind EST where total strain is the sum of elastic and crack strains (equation 4).

$$
\varepsilon=\varepsilon_{e}+\varepsilon_{c r}
$$


The area indicated by $S$ in the figure accounts for the energy dissipated due to microdamage evolution. $G_{c} / l_{e}$ term shows the energy dissipated in the case of failure, where $G_{c}$ is the fracture toughness of the material and $l_{e}$ is the element characteristic length used in the finite element implementation. The EST formulation developed by Pineda and $\mathrm{Waas}^{2}$ is used here and this accounts for three major failure mechanisms: matrix mode I cracking, matrix mode II cracking and axial fiber failure (mode I). Therefore the total work potential of the model can be expressed as a sum of the elastic strain energy, microdamage potential S and the failure potentials denoted by $S_{I}^{m}, S_{I I}^{m}$ and $S_{I}^{f}$. Using CLT this total work potential can be written as,

$$
W=\frac{1}{2}\left(E_{11} \varepsilon_{11}^{2}+E_{22}(S) \varepsilon_{22}^{2}+G_{12}(S) \gamma_{12}^{2}\right)+Q_{12} \varepsilon_{11} \varepsilon_{22}+S_{I}^{m}+S_{I I}^{m}+S_{I}^{f}
$$

According to the assumption of Schapery theory, $E_{22}$ and $G_{12}$, are functions of Schapery microdamge potential, S. Their evolution is shown in the equation 6 , where $e_{s}$ and $g_{s}$ are the functions measured using the approach discussed earlier, in the input parameters section.

$$
\begin{aligned}
E_{22} & =E_{220} e_{s}(S) \\
G_{12} & =G_{120} g_{s}(S)
\end{aligned}
$$

Total energy of the system should be constant with respect to the damage/failure potentials. This principle is used for obtaining the microdamage evolution equation in terms of $S_{r}=S^{(1 / 3)}$ as shown in equation 7 .

$$
\varepsilon_{22}^{2} E_{220} \frac{d e_{s}}{d S_{r}}+\gamma_{12}^{2} G_{120} \frac{d g_{s}}{d S_{r}}=-6 S_{r}^{2}
$$

EST assumes that the damage mechanism won't be active until a transition from damage to failure is effected. The Hashin-Rotem failure criteria are used for determining the failure initiation point. Fiber failure criteria is considered to be independent of the matrix failure criteria and it is give by equation 8 , while the matrix mode I and mode II failure are connected and the mixed mode failure criteria for the matrix is given by, 9 .

$$
\begin{gathered}
\left(\frac{\varepsilon_{11}}{X_{T}}\right)^{2}=1, \quad \varepsilon_{11} \geq 0 \\
\left(\frac{\varepsilon_{11}}{X_{C}}\right)^{2}=1, \quad \varepsilon_{11}<0 \\
\left(\frac{\varepsilon_{22}}{Y_{T}}\right)^{2}+\left(\frac{\gamma_{12}}{Z}\right)^{2}=1, \quad \varepsilon_{22} \geq 0 \\
\left(\frac{\varepsilon_{22}}{Y_{C}}\right)^{2}+\left(\frac{\gamma_{12}}{Z}\right)^{2}=1, \quad \varepsilon_{22}<0
\end{gathered}
$$

When a failure criterion is met, degraded secant stiffness can be computed according to equation 10 . These equations can be derived with the help of figure 3. Mesh objectivity of the model is obtained by smearing the crack energy over the element dimension $l_{e}$, perpendicular to the crack direction.

$$
\begin{array}{ll}
E_{11}=E_{110} \frac{X_{T}\left(\varepsilon_{11 F}-\varepsilon_{11}\right)}{\varepsilon_{11}\left(\varepsilon_{11 F}-X_{T}\right)}, & \varepsilon_{11 F}=\frac{2 G_{I C}^{f}}{E_{110} X_{T}} \\
E_{22}=E_{22}^{*} \frac{Y_{T}\left(\varepsilon_{22 F}-\varepsilon_{22}\right)}{\varepsilon_{11}\left(\varepsilon_{22 F}-Y_{T}\right)}, & \varepsilon_{11 F}=\frac{2 G_{I C}^{m}}{E_{22}^{*} Y_{T}} \\
G_{12}=G_{12}^{*} \frac{Z\left(\gamma_{12 F}-\gamma_{12}\right)}{\gamma_{12}\left(\gamma_{12 F}-Z\right)}, & \gamma_{12 F}=\frac{2 G_{I I C}^{m}}{G_{12}^{*} Z}
\end{array}
$$

Larger element characteristic length $l_{e}$ can cause the area under the stress strain curve to decrease and can cause a vertical stress drop at a critical value. An element of length larger than this critical value will 
lead to physically incorrect snap-back behavior. The critical element length to prevent this condition is given by,

$$
l_{e}<\min \left\{\frac{2 G_{I C}^{f}}{E_{110} X_{T}^{2}}, \frac{2 G_{I C}^{m}}{E_{22}^{*} Y_{T}^{2}}, \frac{2 G_{I I C}^{m}}{G_{12}^{*} Z^{2}}\right\}
$$

Mesh size should be carefully chosen when working with crack band model so that the issues related to negative post-peak slope can be avoided. In this study mesh size was chosen such that it is one order of magnitude less than the crack band element characteristic length given in equation 11.

\section{Results and Discussion}

All the open hole tension and compression tests were carried out as per ASTM standards D5766 and D6484 respectively. Extensometer of 2" gage length was used for measuring the displacements at points located 1" away from the hole on each side in the loading direction. Displacements are measured from the finite element models at the locations corresponding to extensometer heads to compare the load-displacement response with the test data for all the cases. Progression of failure events are also listed along with the loaddisplacement plots. Sequence of failure initiations are the same between the layups, but the extensometer displacements corresponding to these events are different between laminates as it depends on the stress distribution near the hole. As we go from stiffer to softer laminates, 0 layer fiber failure initiation occurs at higher displacement value. This has to be expected since the softer laminate will have a smaller stress concentration near the hole. For an open hole coupon under tensile loading, transverse failure initiation in 90 layer is the first failure event in all the laminates and this degrades the transverse stiffness in that layer which in turn increases the stresses in the 45 and 0 layers. Increased stress in the 45 layer forces it to have a transverse/shear failure initiation and this leads to a fiber failure initiation in the 0 layer. This sequence of events lead to the final complete failure of the 0 layer in fiber direction and two-piece failure ensues.

Load-displacement comparison for the stiff 50/40/10 laminate is shown in figure 4. Strength predicted by EST is within the error bounds of the experiment, however there is a mismatch in the slope of the curve. Experimental data shows a small stiffening behavior while EST shows some non-linear softening behavior due to the matrix microdamage evolution and also due to the progressive failure in 90 and 45 layers. The stiffening effect seen in the experiment can be attributed to the elastic stiffening of the carbon fibers reported in the literature, ${ }^{7}$ while the EST model does not account for this behavior of the fibers. However this effect is not very significant and is not observed in open hole testing of the other layups. Final failure patterns in all the layers of the laminate are compared with the actual failed specimen in figure 5 . Within the limitation of a shell theory, EST is able to capture the failure patterns quite accurately.

The peak load predicted by EST for the medium stiff 25/50/25 laminate is about $11 \%$ higher than the test results (figure6). Compared to the other 2 layups, this layup has the most number of 45/90 interfaces and hence this is more prone to delamination because of the earlier in-plane failure initiation in 90 and 45 layers. Hence allowing delamination mode of failure is critical in getting an accurate prediction for this layup. In order for the EST simulation to match with the test result, fiber direction fracture toughness can be further reduced which is an indirect way of accounting for the energy loss due to delamination. Final failure pattern for this layup is also compared with the test specimen in figure 7 .

For the soft 10/80/10 laminate, EST under-predicts the peak load as shown in figure 8. +45/-45 interfaces present in this particular layup differentiates it from the other layups. $+45 /-45$ interface offers more resistance towards delamination than all the other interfaces present. In order to account for this extra resistance, fiber direction fracture toughness can be increased so that EST prediction matches with the test data. Increasing the fiber direction fracture toughness from $8.6 \mathrm{~N} / \mathrm{mm}$ to $12.0 \mathrm{~N} / \mathrm{mm}$ makes the prediction close to the test result. Final failure pattern shown in figure 9 agrees very well with the failure of the actual test specimen.

The sequence of failure events are seen to change when the remote loading changes from tension to compression. Since the transverse failure strain in compression is fairly large, fiber failure initiation becomes the first failure event which is shortly followed by the transverse/shear failure initiation in the 45 layer. Final catastrophic failure occurs due to the complete fiber failure in the 0 layer under compression. Past studies have shown the micromechanics of open hole failure in compression, captured through a global-local approach, sometimes referred to in the literature as an embedded element method. Fiber kink banding is dominant and this is accurately captured in the open hole models by Ahn and Waas ${ }^{12}$ and also by Davidson et al. ${ }^{1}$ 
In the present studies, the kink banding toughness is modeled as the overstress fiber direction toughness in compression. The open hole compression strength prediction for the 50/40/10 laminate agrees well with the test results as shown in figure 11. The trend for compressive strength predictions are similar to the tensile cases. Compressive strength of the 25/50/25 is over-predicted (figure 12) similar to it's tensile counterpart. For the softer 10/80/10 laminate, EST under-predicts the strength as shown in figure 14. Final pattern comparisons for the 50/40/10,25/50/25 and 10/80/10 laminates are shown in figures 11,13 and 15 , respectively. Load-displacement curves for all the open hole compression cases show a significant nonlinear behavior, while the EST model shows mild nonlinearity. This difference can be due to the difference in matrix non-linearity between tensile and compressive loading cases. In this study matrix non-linear behavior is assumed be the same in both tension and compression. Figures 16 and 17, and table 4 summarizes results of the open hole strength predictions for all the laminates.

\section{Conclusion}

Enahnced Schapery Theory (EST) is a computationally efficient effective model for capturing the in-plane failure in a composite laminate with stress concentrations due to holes/notches. All the layers in a composite laminate can be modeled using a single shell element in this approach which reduces the computational time by a large margin. Capability of the EST model to predict the open hole strength from coupon level test data is demonstrated for the three different layups of IM7/8552 material. Another advantage of EST is the unified modeling approach for both tension and compression. Within the limitations of a shell model, agreement of the predictions with the test results is excellent. The difficulties and limitation of using a shell model for failure analysis are also addressed here. When delamination becomes a key failure mechanism, error in the predictions can be high. In those instances, this can be overcome to a certain extent by scaling the fiber direction fracture toughness as a laminate property as demonstrated here. A more physically reasonable approach would be introducing cohesive elements between the EST shell layers at the critical interfaces to account for the delamination. This approach will be computationally more expensive than the single shell EST approach, but still much faster than modeling with 3D elements. This modeling strategy is currently being investigated.

\section{Acknowledgments}

The authors are grateful for sponsorship from the Boeing company. Useful discussions with Steve Precup, Mostafa Rassaian and Gerry Mabson are gratefully acknowledged.

\section{References}

\footnotetext{
${ }^{1}$ Davidson, P., Pineda, E. J., Heinrich, C., and Waas, A. M., "A unified model for predicting the open hole tensile and compressive strengths of composite laminates for aerospace applications," AIAA/ASME/ASCE/AHS/ASC 54th Structures, Structural Dynamics, and Materials Conference, Boston, MA, 2013.

${ }^{2}$ Pineda, E. J. and Waas, A. M., "Numerical implementation of a multiple-ISV thermodynamically-based work potential theory for modeling progressive damage and failure in fiber-reinforced laminates," International Journal of Fracture, Vol. 182, No. 1, 2013, pp. 93-122.

${ }^{3}$ Bazant, Z. P. and Oh, B. H., "Crack band theory for fracture of concrete," Materiaux et constructions, Vol. 16, No. 93, pp. $155-177$.

${ }^{4}$ Camanho, P. P. and Catalanotti, G., "On the relation between the mode I fracture toughness of a compoiste laminate and that of a 0 py; Analytical model and Experimental Validation," Engineering Fracture Mechanics, Vol. 78, 2011, pp. 2535-2546.

${ }^{5}$ Marlette, K., "Hexcel 8552 IM7 Unidrectional Prepreg 190 gsm \& 35Qualification Material Poperty Data Report," Ncamp test report cam-rp-2009-015 rev a, NIAR, Wichita State university, 2011.

${ }^{6}$ Schapery, R. A., "A theory of mechanical behavior of elastic media with growing damage and other changes in structure," Journal of Mechanics and Physics of Solids, Vol. 38, No. 2, 1990, pp. 215-153.

${ }^{7}$ Sicking, D. L., Mechanical characterization of nonlinear laminated composites with transverse crack growth, Ph.D. thesis, Texas A\&M University, College Station, Texas, 1992.

${ }^{8} \mathrm{Ng}$, W. H., Salvi, A. G., and Waas, A. M., "Characterization of the in-situ non-linear shear response of laminated fiber-reinforced composites," Composites Science and Technology, Vol. 70, 2010, pp. 1126-1134.

${ }^{9}$ Sutcliffe, M. P. F., Lemanski, S. L., and Scott, A. E., "Measurement of fiber waviness in industrial composite components," Composites Science and Technology, Vol. 72.

${ }^{10}$ Boyd, S., Ji, W., Joseph, A. P. K., and Waas, A. M., "Single edge notch tension test on cross-ply laminated composites for intralaminar fracture properties," 55th AIAA/ASME/ASCE/AHS/SC Structures, Structural Dynamics, and Materials Conference, National Harbor, Maryland, 2014.
} 
${ }^{11} \mathrm{Xu}, \mathrm{W}$. and Waas, A. M., "On the crack band model and its practical implementation in commercial finite element codes," Engineering Fracture Mechanics (to be published), 2014.

${ }^{12} \mathrm{Ahn}$, J. H. and Waas, A. M., "Prediction of compressive failure in laminated composites at room and elevated temperature," AIAA Journal, Vol. 40, No. 2, 2002, pp. 346-358.

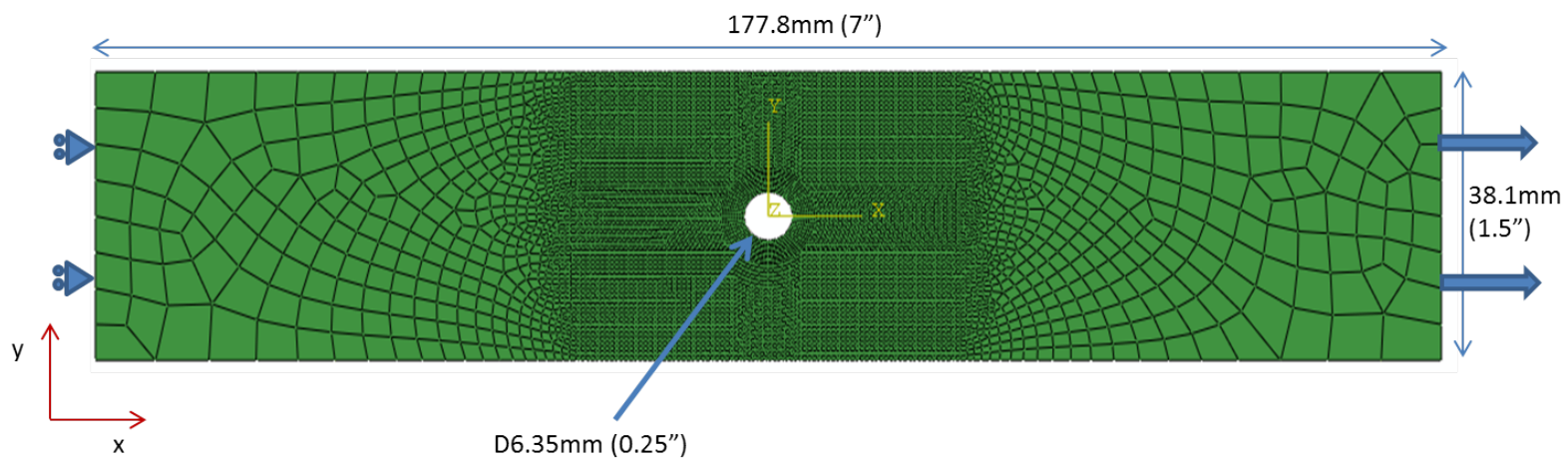

Figure 1. Finite element model

\begin{tabular}{|c|c|}
\hline $\begin{array}{c}\text { Laminate } \\
\text { (\% 0 plies /\% } \pm \mathbf{4 5} \text { plies } / \% \text { 90 plies) }\end{array}$ & Lay-up \\
\hline $50 / 40 / 10$ & {$[0 / 45 / 0 / 90 / 0 /-45 / 0 / 45 / 0 /-45] s$} \\
\hline $25 / 50 / 25$ & {$[45 / 0 /-45 / 90] 2 s$} \\
\hline $10 / 80 / 10$ & {$[45 /-45 / 0 / 45 /-45 / 90 / 45 /-45 / 45 /-45] s$} \\
\hline
\end{tabular}

Table 1. List of laminates studied 


\begin{tabular}{|c|c|c|}
\hline \multicolumn{2}{|c|}{$\begin{array}{l}\text { Schapery Curves } \\
\left(P a^{-1 / 3}\right)\end{array}$} & Remark \\
\hline es0 & 1.0 & \multirow{6}{*}{$\begin{array}{l}\text { Transverse damage } \\
\text { coefficients in } \\
\text { tension/compression. } \\
\text { Calculated from virtual } \\
\text { transverse test of RUC using } \\
\pm 45^{\circ} \text { tension test results }\end{array}$} \\
\hline es1 & $-1.32 \mathrm{E}-3$ & \\
\hline es2 & $-5.7 \mathrm{E}-5$ & \\
\hline es3 & $-3.29 E-7$ & \\
\hline es 4 & $-6.94 \mathrm{E}-10$ & \\
\hline es5 & 0.0 & \\
\hline gs0 & 1.0 & \multirow{6}{*}{$\begin{array}{l}\text { Shear damage coefficients. } \\
\text { Calculated from } \pm 45^{\circ} \text { tension } \\
\text { test }\end{array}$} \\
\hline gs1 & $-7.36 \mathrm{E}-3$ & \\
\hline gs2 & $2.7 \mathrm{E}-5$ & \\
\hline gs3 & $4.76 \mathrm{E}-7$ & \\
\hline gs4 & $1.28 \mathrm{E}-9$ & \\
\hline gs5 & $3.56 \mathrm{E}-11$ & \\
\hline
\end{tabular}

Table 2. Schapery microdamage functions 


\begin{tabular}{|c|c|c|}
\hline Property & $\begin{array}{l}\text { Value } \\
\text { (Units- SI) }\end{array}$ & Remark \\
\hline \multicolumn{3}{|c|}{ Lamina Properties } \\
\hline $\mathrm{E}_{11}$ & $\begin{array}{r}154.46 \mathrm{E}+09 \\
(140.9 \mathrm{E}+09)\end{array}$ & $\begin{array}{l}{\left[90^{\circ} / 0^{\circ}\right]_{5} \text { Tension Test }} \\
\text { (NIAR Report - } 0^{\circ} \text { Compression Test ) }\end{array}$ \\
\hline $\mathrm{E}_{22}$ & $7.20 \mathrm{E}+09$ & $90^{\circ}$ Tension Test \\
\hline $\mathrm{v}_{12}$ & 0.34 & $0^{\circ}$ Tension Test \\
\hline $\mathrm{G}_{12}$ & $4.87 \mathrm{E}+09$ & $\pm 45^{\circ}$ Tension Test \\
\hline \multicolumn{3}{|c|}{ Failure Properties } \\
\hline$X_{T}$ & 0.0147 & $0^{\circ}$ Tension Test \\
\hline$X_{C}$ & 0.0131 & Predicted for $1.2^{\circ}$ fiber misalignment \\
\hline $\mathrm{Y}_{T}$ & 0.0080 & $90^{\circ}$ Tension Test \\
\hline $\mathrm{Y}_{C}$ & 0.0462 & $90^{\circ}$ Compression Test \\
\hline$Z$ & 0.0227 & $\pm 45^{\circ}$ Tension Test \\
\hline \multicolumn{3}{|c|}{ Fracture Toughness } \\
\hline$G_{I T}^{\mathrm{f}}$ & $\begin{array}{c}40.5 \mathrm{E}+3 \\
21.0 \mathrm{E}+3 \\
8.6 \mathrm{E}+3\end{array}$ & $\begin{array}{l}\text { For } 50 / 40 / 10,25 / 50 / 25 \text { and } 10 / 80 / 10 \\
\text { laminates respectively }\end{array}$ \\
\hline$G_{I C}^{\mathrm{f}}$ & $\begin{array}{c}10.1 \mathrm{E}+3 \\
5.3 \mathrm{E}+3 \\
2.2 \mathrm{E}+3\end{array}$ & $\begin{array}{l}\text { For } 50 / 40 / 10,25 / 50 / 25 \text { and } 10 / 80 / 10 \\
\text { laminates respectively }\end{array}$ \\
\hline$G_{I T}^{\mathrm{m}}$ & $0.384 \mathrm{E}+3$ & DCB Test \\
\hline$G_{I C}^{m}$ & $0.384 \mathrm{E}+3$ & Assumed same as tension \\
\hline$G_{I I}^{\mathrm{m}}$ & $2.184 \mathrm{E}+3$ & ENF Test \\
\hline
\end{tabular}

Table 3. Material properties for EST 


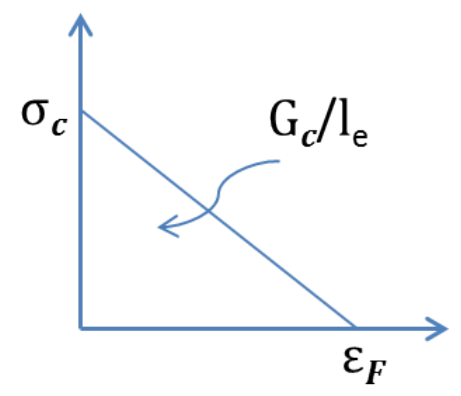

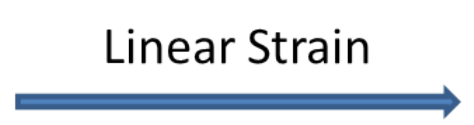

Traction-crack strain to Traction-separation
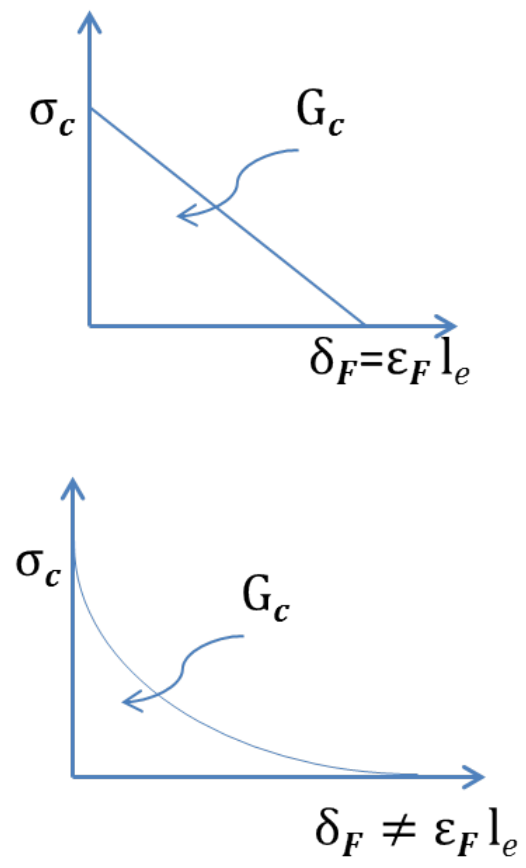

Figure 2. Fracture toughness correction for logarithmic strain
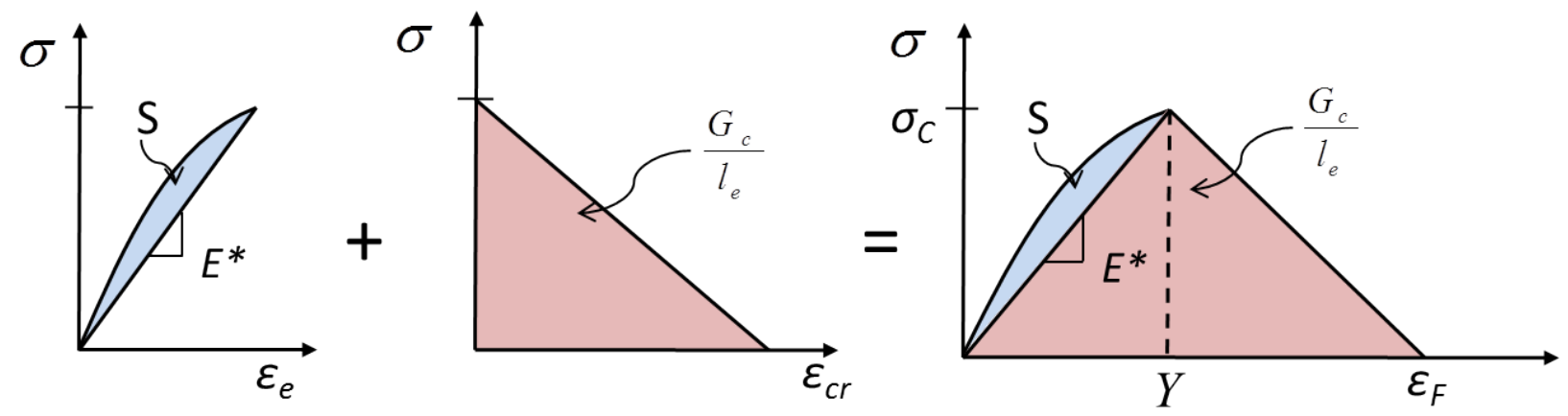

Figure 3. Stress-strain response of EST element

\begin{tabular}{|c|c|c|c|c|c|}
\hline \multirow{2}{*}{ Case } & \multicolumn{3}{|c|}{ Peak Stress [MPa] } & \multicolumn{2}{c|}{ Modulus [GPa] } \\
\cline { 2 - 6 } & $\begin{array}{c}\text { EST } \\
\text { Prediction }\end{array}$ & $\begin{array}{c}\text { Test } \\
\text { Data }\end{array}$ & $\begin{array}{c}\text { NIAR } \\
\text { Report }\end{array}$ & $\begin{array}{c}\text { EST } \\
\text { Prediction }\end{array}$ & $\begin{array}{c}\text { Test } \\
\text { Data }\end{array}$ \\
\hline OHT 50/40/10 & 652.2 & $628.1 \pm 21.4$ & $597.0 \pm 34.1$ & 82.9 & $90.3 \pm 4.3$ \\
\hline OHT 25/50/25 & 480.0 & $432.8 \pm 12.4$ & $406.8 \pm 11.3$ & 54.6 & $57.2 \pm 6.6$ \\
\hline OHT 10/80/10 & 284.8 & $315.9 \pm 3.9$ & $301.0 \pm 12.3$ & 35.1 & $37.2 \pm 2.8$ \\
\hline OHC 50/40/10 & 457.1 & $455.8 \pm 24.1$ & $436.9 \pm 18.7$ & 76.3 & $83.4 \pm 9.0$ \\
\hline OHC 25/50/25 & 394.4 & $346.1 \pm 7.6$ & $337.1 \pm 10.0$ & 50.9 & $51.7 \pm 5.6$ \\
\hline OHC 10/80/10 & 277.1 & $289.7 \pm 5.2$ & $264.8 \pm 9.0$ & 33.2 & $33.8 \pm 4.7$ \\
\hline
\end{tabular}

Table 4. Open hole tension/compression results summary 

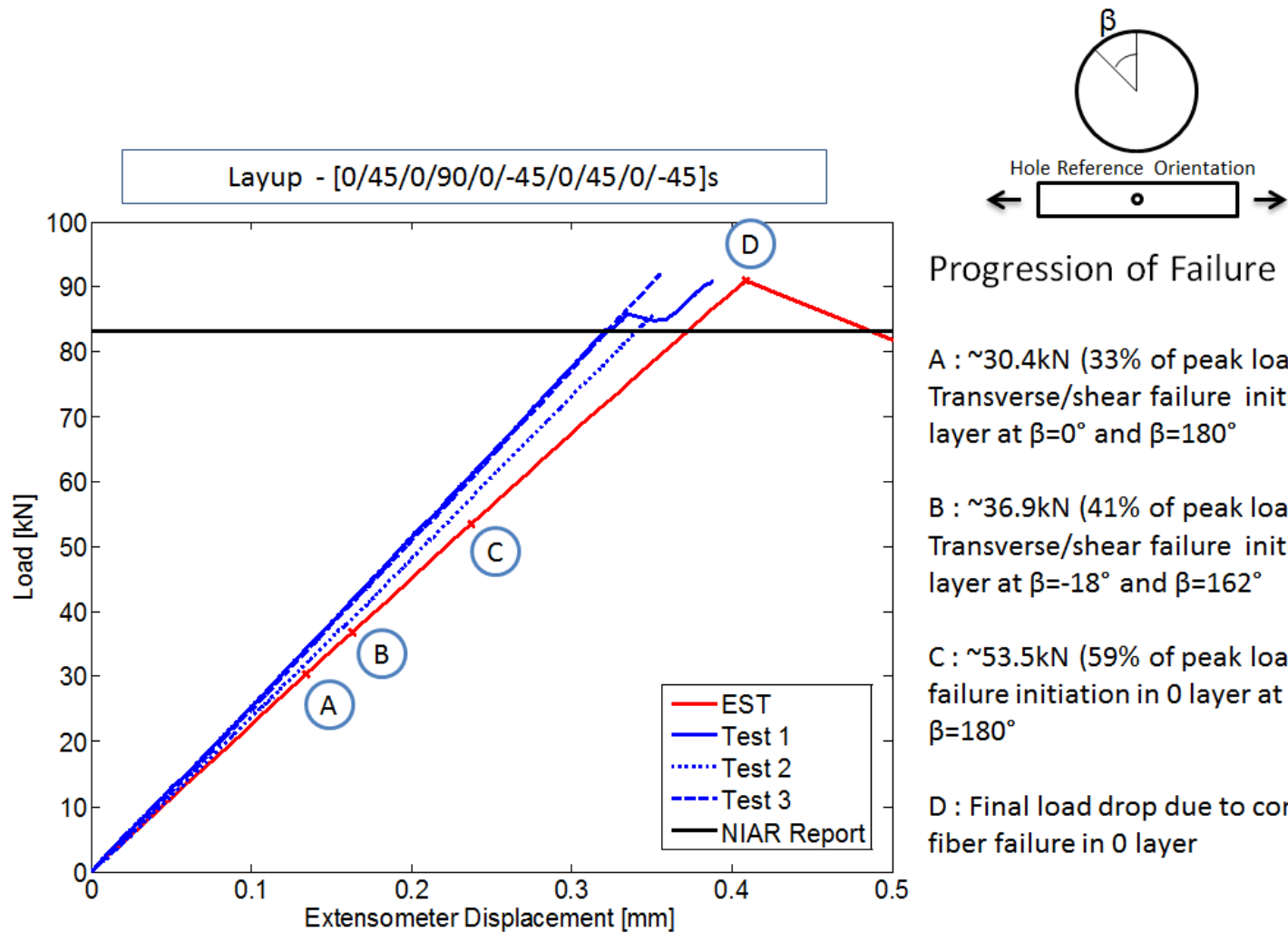

Progression of Failure

A : $\sim 30.4 \mathrm{kN}$ (33\% of peak load)

Transverse/shear failure initiation in 90 layer at $\beta=0^{\circ}$ and $\beta=180^{\circ}$

B : $\sim 36.9 \mathrm{kN}$ (41\% of peak load)

Transverse/shear failure initiation in 45 layer at $\beta=-18^{\circ}$ and $\beta=162^{\circ}$

C: $\sim 53.5 \mathrm{kN}$ (59\% of peak load) Fiber failure initiation in 0 layer at $\beta=0^{\circ}$ and $\beta=180^{\circ}$

D : Final load drop due to complete fiber failure in 0 layer

Figure 4. Load-displacement plot for open hole tension of 50/40/10 laminate coupon

Transverse/Shear Failure
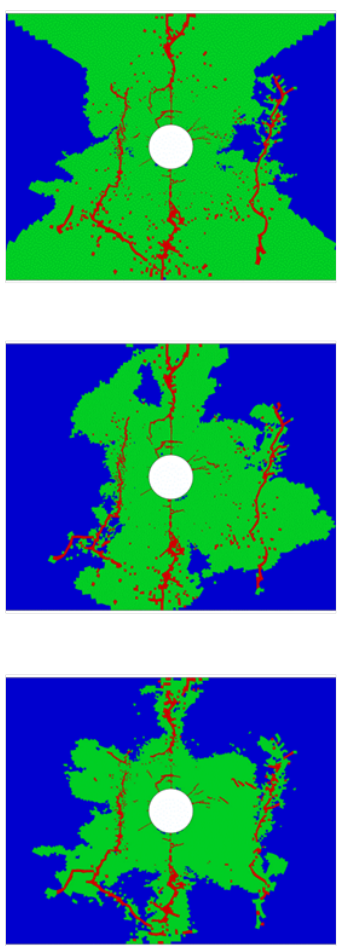

Fiber Failure
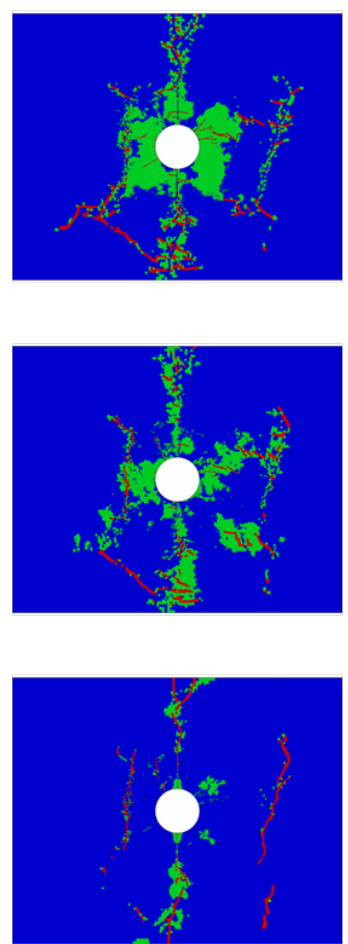

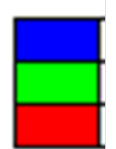

Undamaged

Post Peak Softening (Failure Initiation)

Completely Failed

\section{Test Specimen}

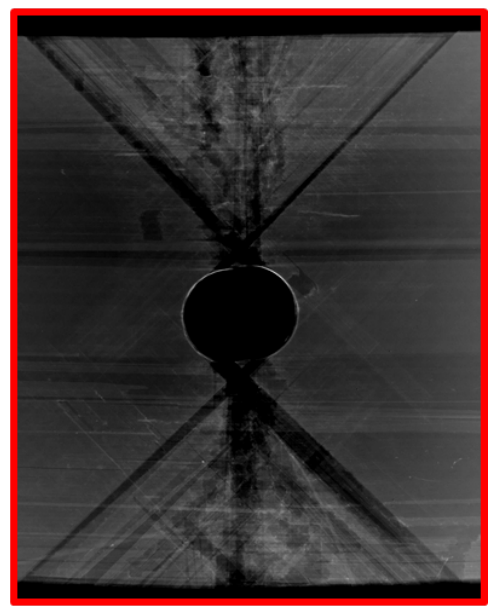

Figure 5. Failure of 50/40/10 laminate coupon under tension 

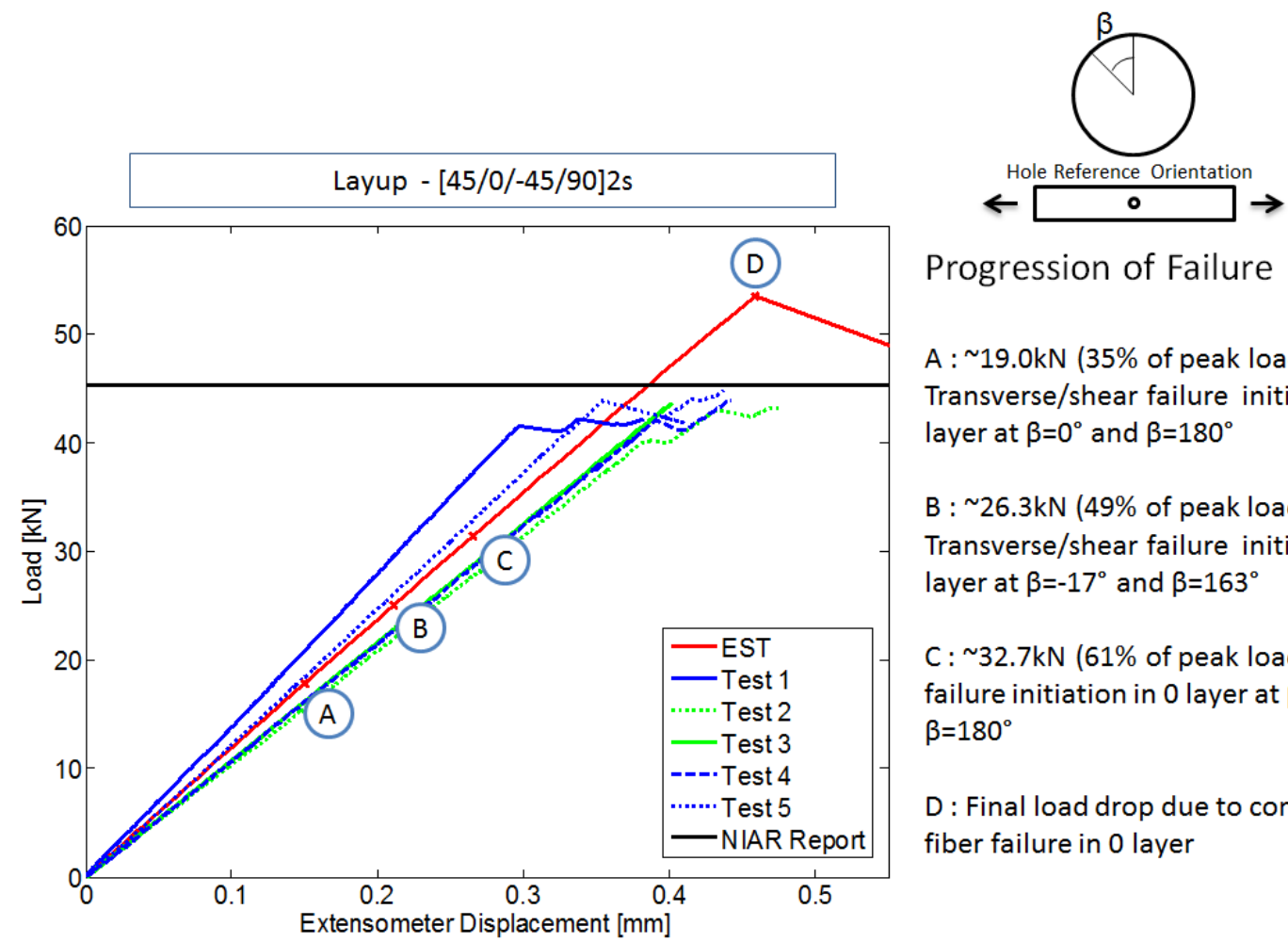

\section{Progression of Failure}

A : $19.0 \mathrm{kN}$ (35\% of peak load)

Transverse/shear failure initiation in 90 layer at $\beta=0^{\circ}$ and $\beta=180^{\circ}$

B : 26.3kN (49\% of peak load)

Transverse/shear failure initiation in 45 layer at $\beta=-17^{\circ}$ and $\beta=163^{\circ}$

C: $\sim 32.7 \mathrm{kN}$ (61\% of peak load) Fiber failure initiation in 0 layer at $\beta=0^{\circ}$ and $\beta=180^{\circ}$

D : Final load drop due to complete fiber failure in 0 layer

Figure 6. Load-displacement plot for open hole tension of 25/50/25 laminate coupon

Transverse/Shear Failure
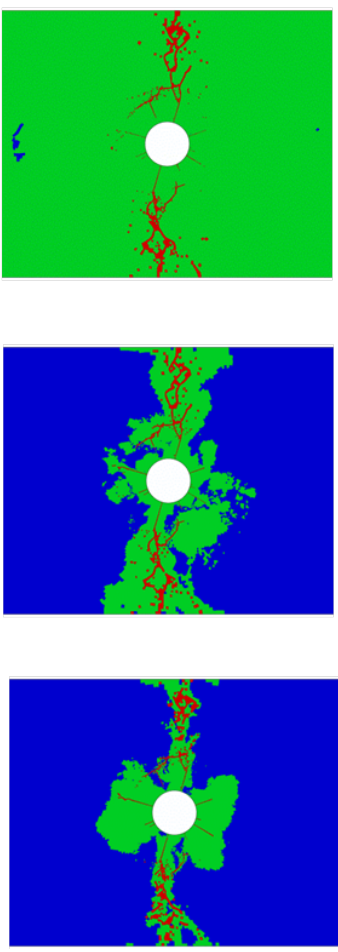

Fiber Failure
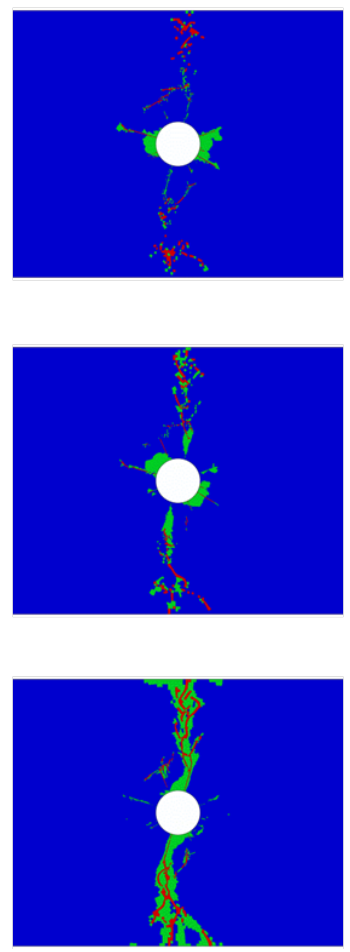

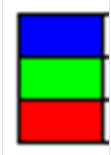

Undamaged

Post Peak Softening (Failure Initiation)

Completely Failed

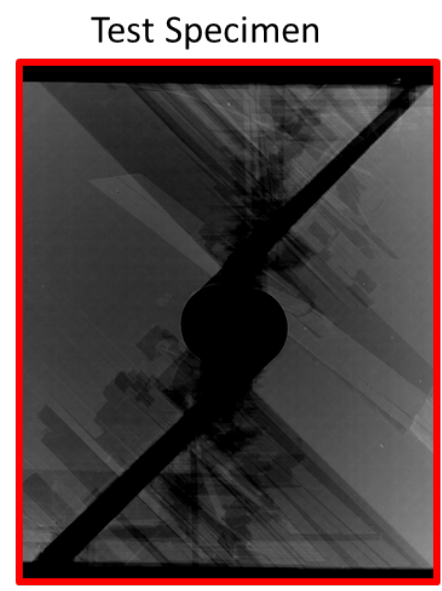

0 layer

Figure 7. Failure of 25/50/25 laminate coupon under tension 

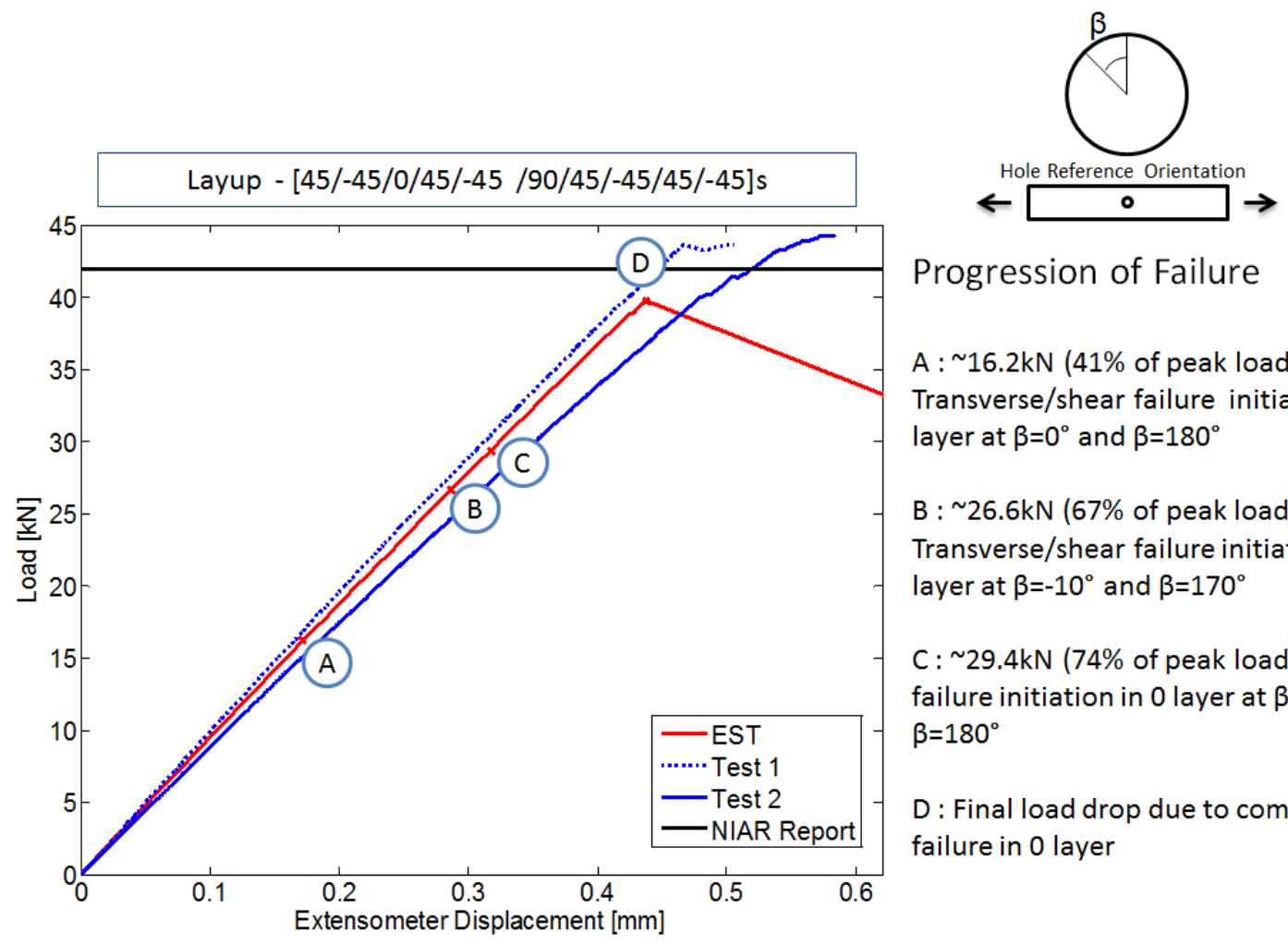

Progression of Failure

A : $~ 16.2 \mathrm{kN}$ (41\% of peak load)

Transverse/shear failure initiation in 90 layer at $\beta=0^{\circ}$ and $\beta=180^{\circ}$

\section{B : $26.6 \mathrm{kN}$ (67\% of peak load)}

Transverse/shear failure initiation in 45 layer at $\beta=-10^{\circ}$ and $\beta=170^{\circ}$

C : $\sim 29.4 \mathrm{kN}$ (74\% of peak load) Fiber failure initiation in 0 layer at $\beta=0^{\circ}$ and $\beta=180^{\circ}$

D : Final load drop due to complete fiber failure in 0 layer

Figure 8. Load-displacement plot for open hole tension of 10/80/10 laminate coupon

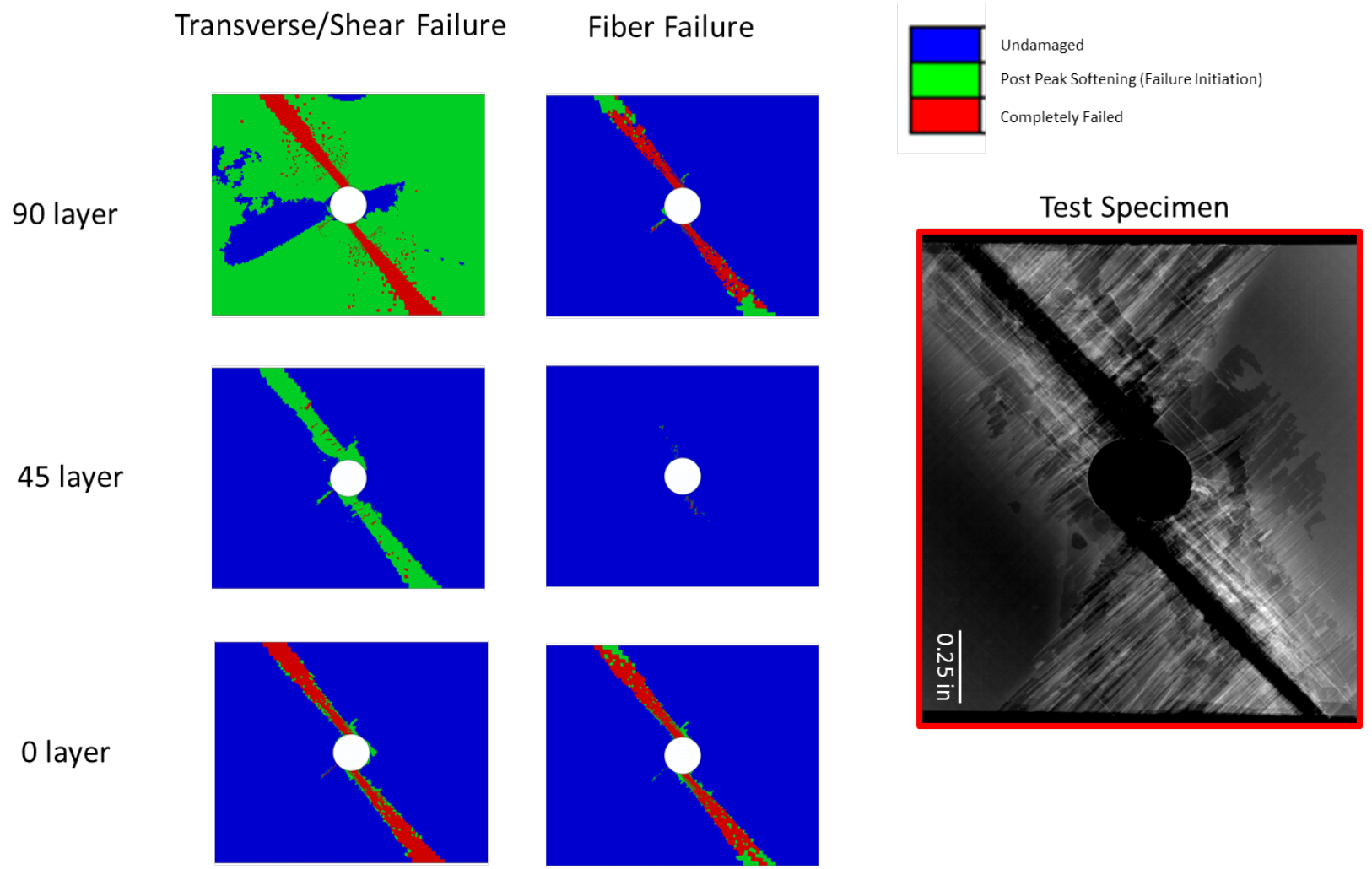

Figure 9. Failure of 10/80/10 laminate coupon under tension 

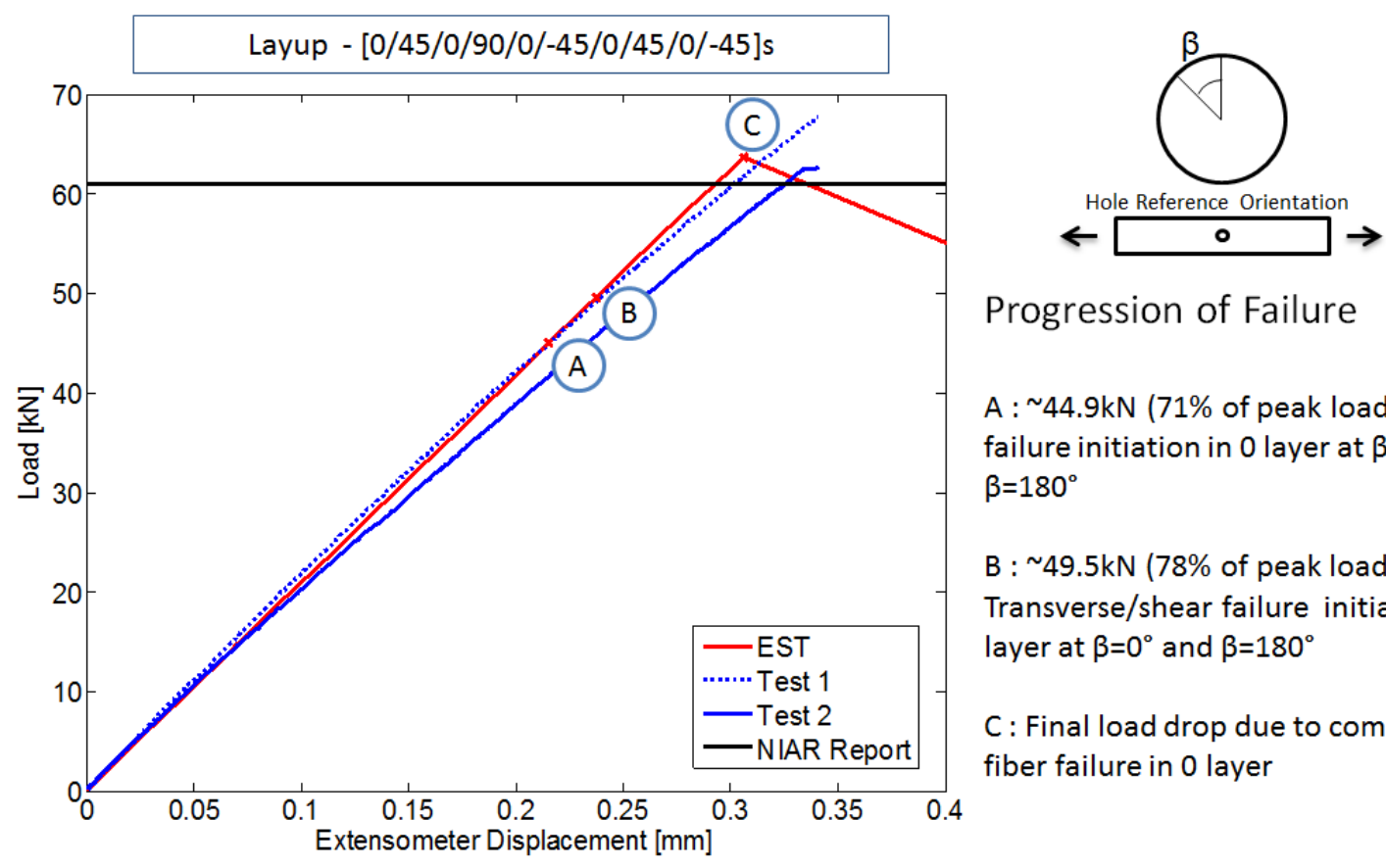

Progression of Failure

A : $\sim 44.9 \mathrm{kN}$ (71\% of peak load) Fiber failure initiation in 0 layer at $\beta=0^{\circ}$ and $\beta=180^{\circ}$

B : $49.5 \mathrm{kN}$ (78\% of peak load)

Transverse/shear failure initiation in 45 layer at $\beta=0^{\circ}$ and $\beta=180^{\circ}$

C : Final load drop due to complete fiber failure in 0 layer

Figure 10. Load-displacement plot for open hole compression of 50/40/10 laminate coupon

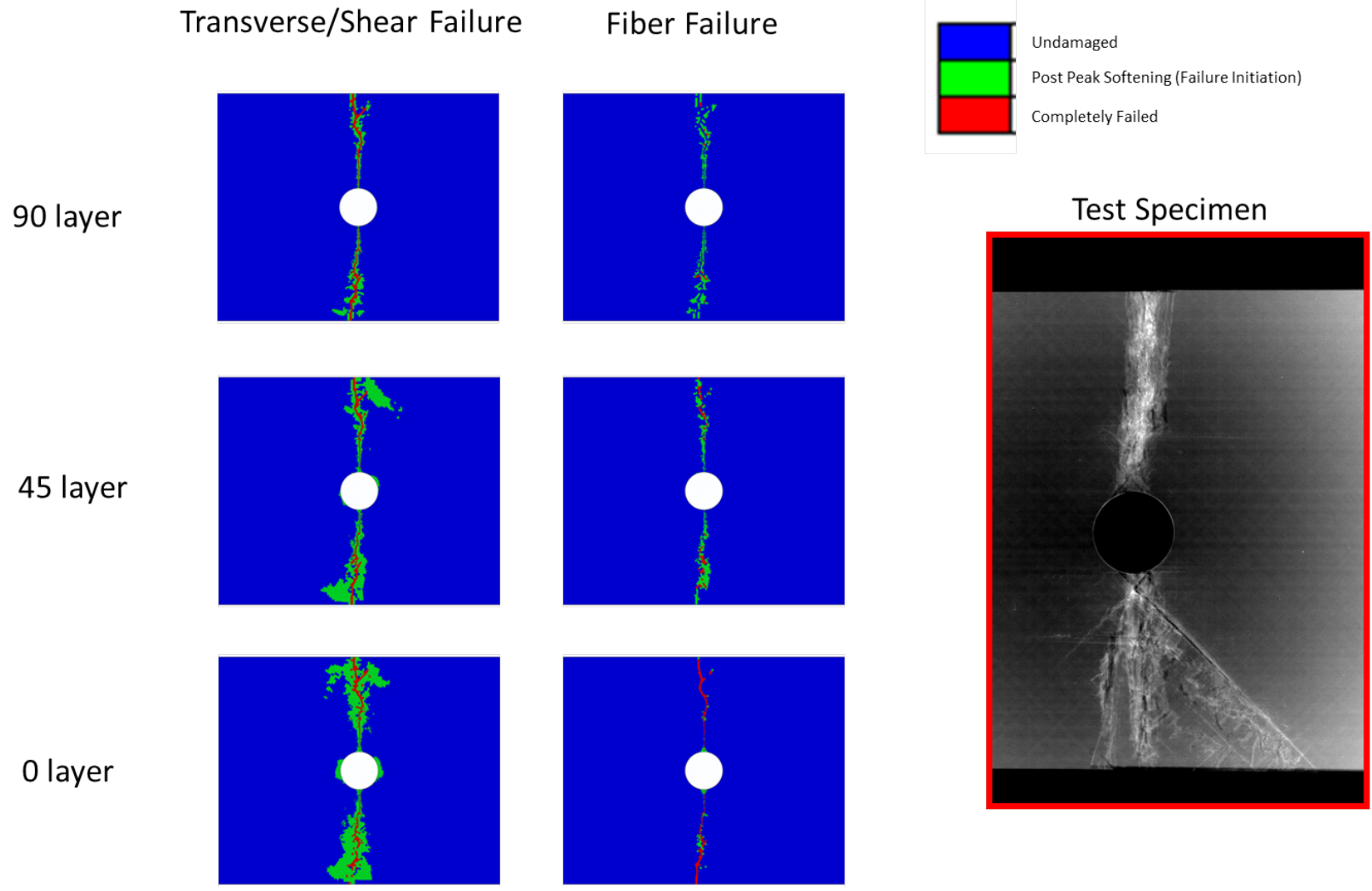

Figure 11. Failure of 50/40/10 laminate coupon under compression 

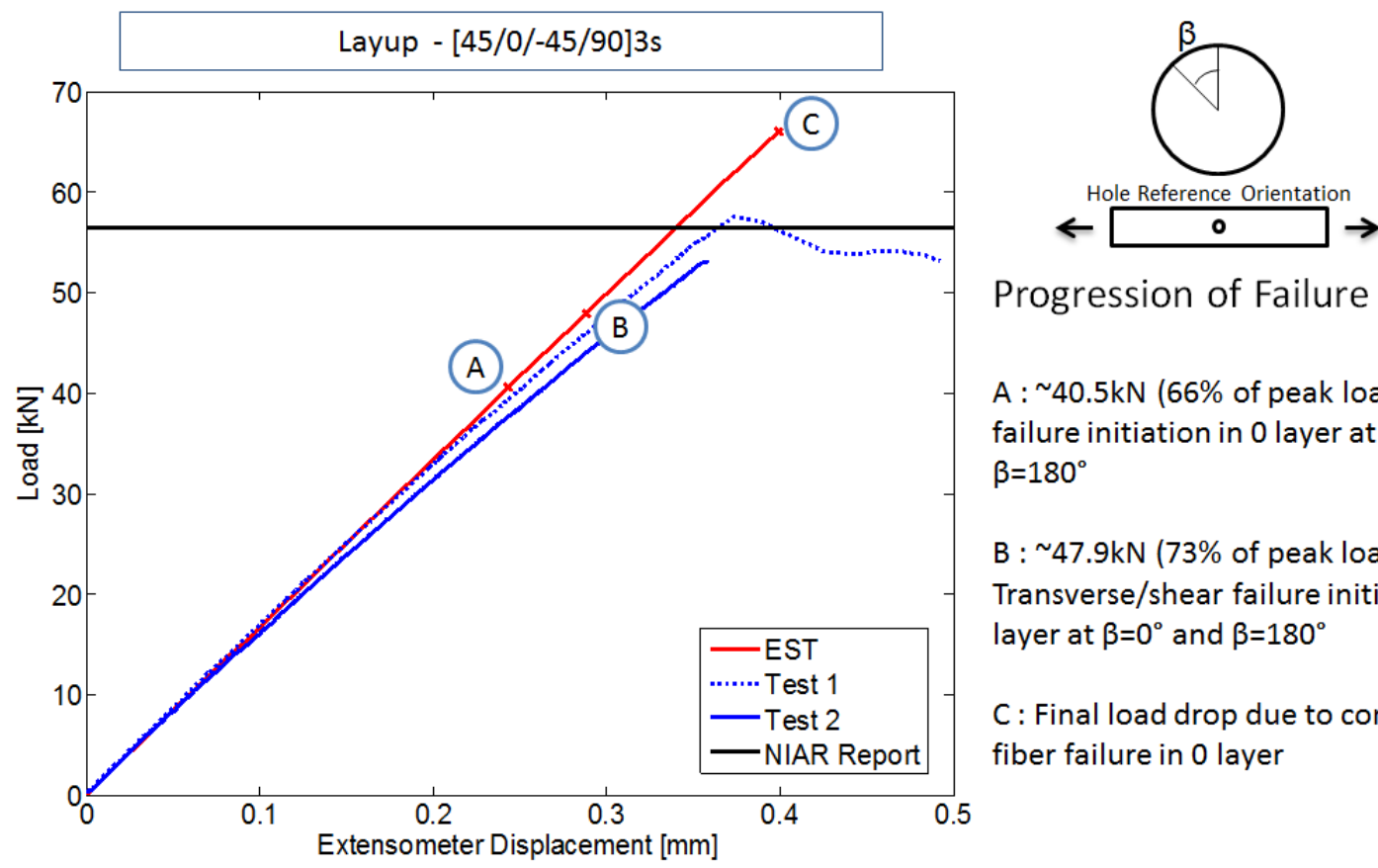

Progression of Failure

A : $\sim 40.5 \mathrm{kN}$ ( $66 \%$ of peak load) Fiber failure initiation in 0 layer at $\beta=0^{\circ}$ and $\beta=180^{\circ}$

B : $47.9 \mathrm{kN}$ (73\% of peak load)

Transverse/shear failure initiation in 45 layer at $\beta=0^{\circ}$ and $\beta=180^{\circ}$

C : Final load drop due to complete fiber failure in 0 layer

Figure 12. Load-displacement plot for open hole compression of 25/50/25 laminate coupon

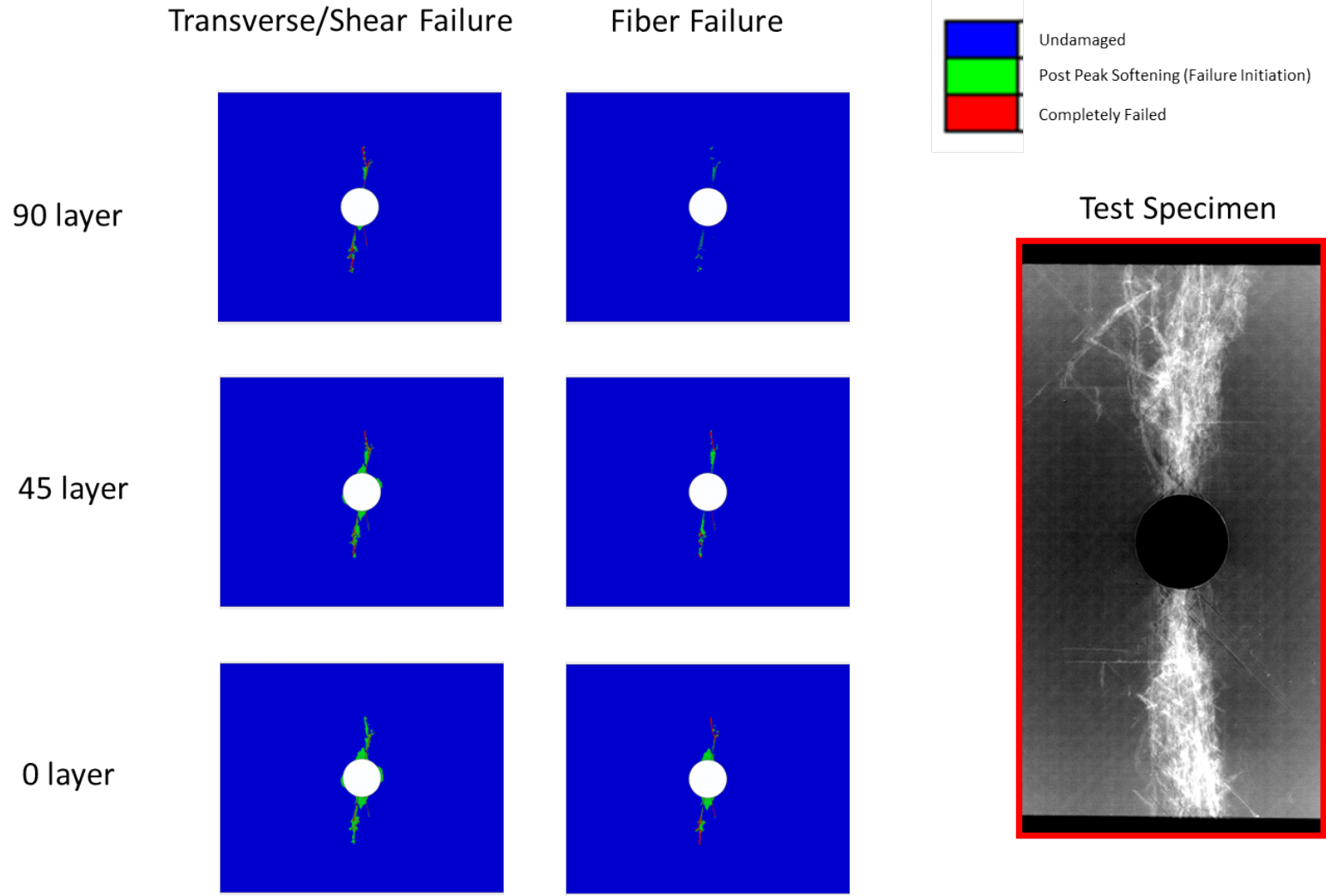

Figure 13. Failure of 25/50/25 laminate coupon under compression 

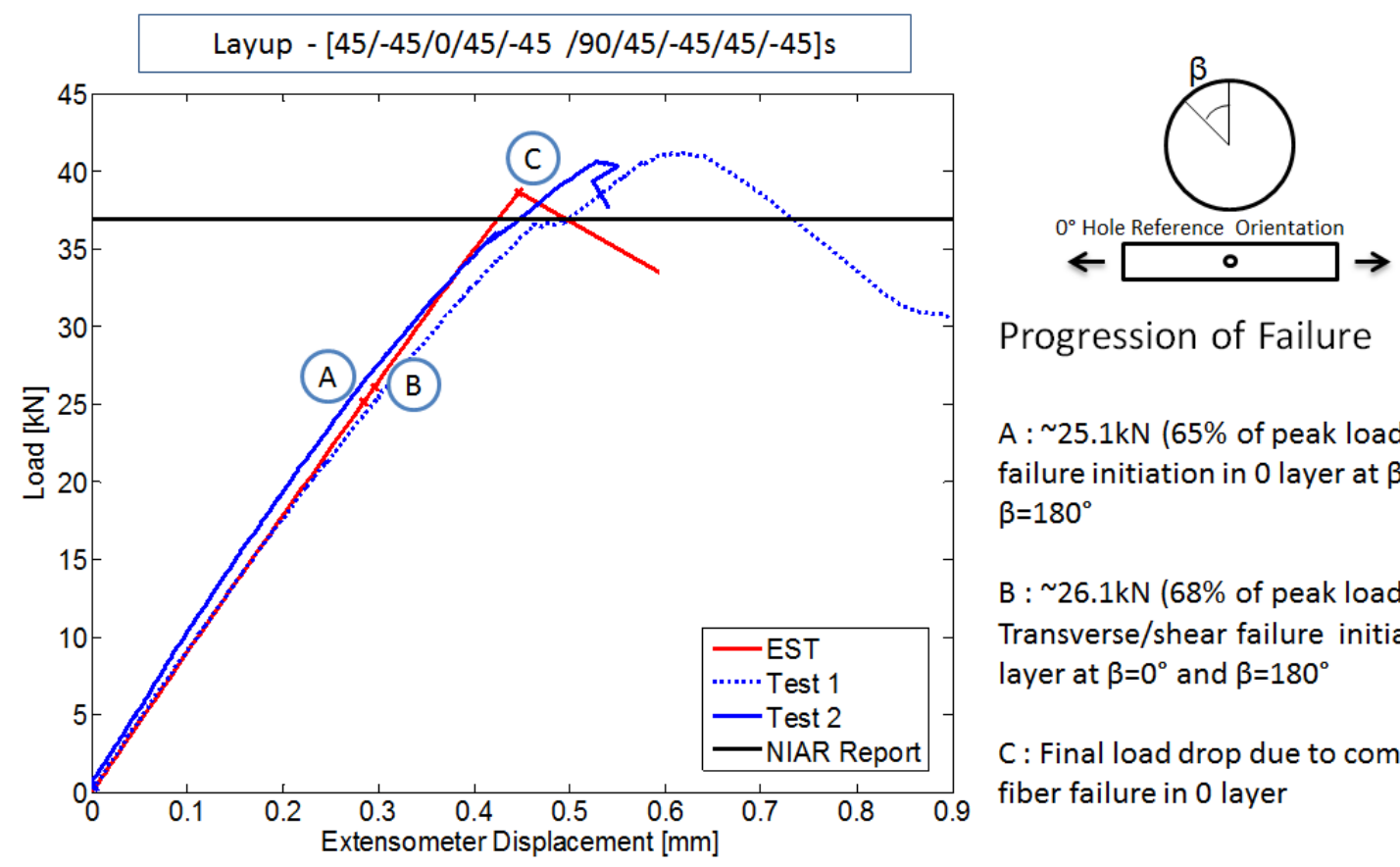

A : $\sim 25.1 \mathrm{kN}$ (65\% of peak load) Fiber failure initiation in 0 layer at $\beta=0^{\circ}$ and $\beta=180^{\circ}$

B : $26.1 \mathrm{kN}$ (68\% of peak load)

Transverse/shear failure initiation in 45

layer at $\beta=0^{\circ}$ and $\beta=180^{\circ}$

C : Final load drop due to complete fiber failure in 0 layer

Figure 14. Load-displacement plot for open hole compression of 10/80/10 laminate coupon

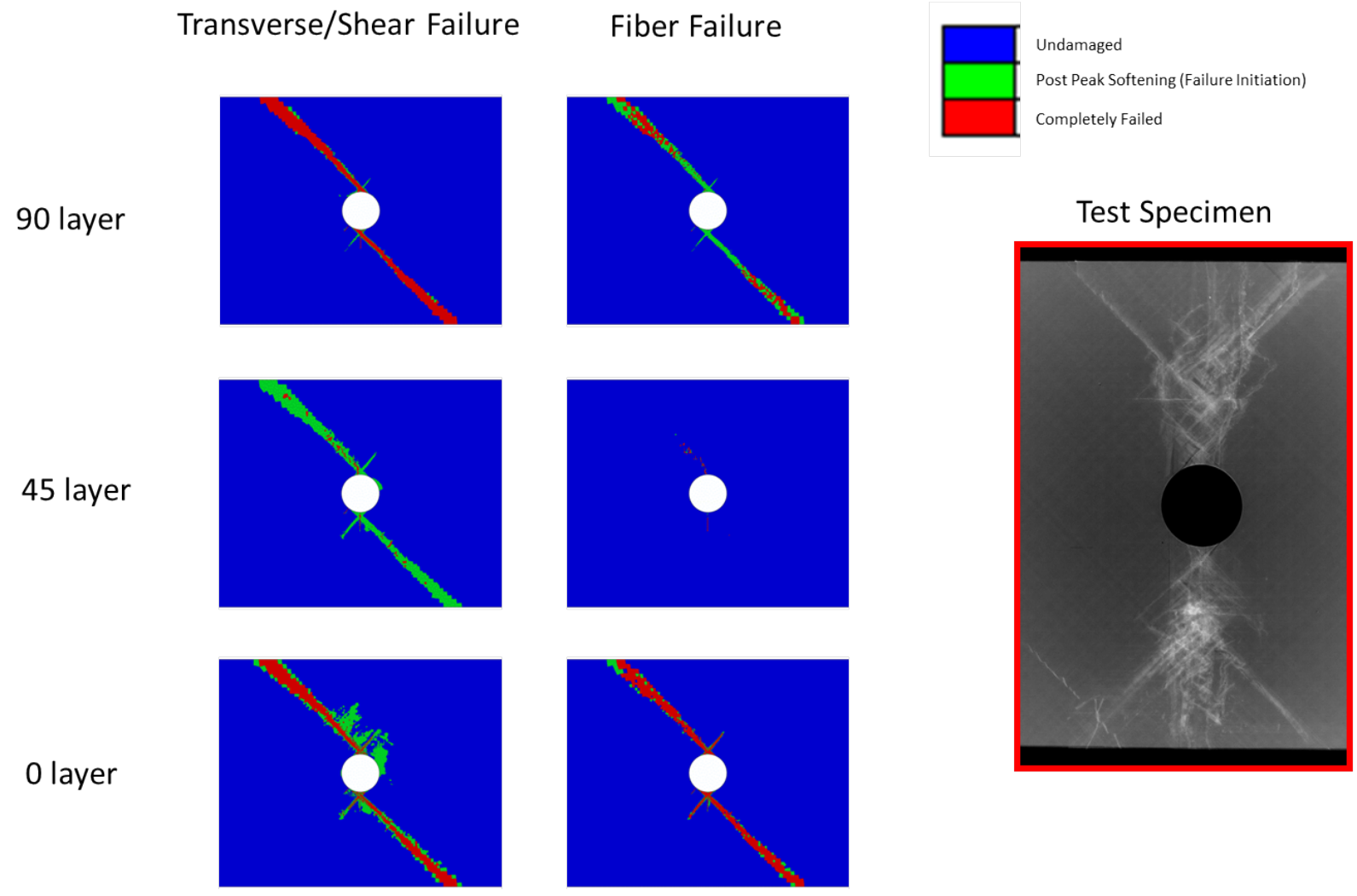

Figure 15. Failure of 10/80/10 laminate coupon under compression 


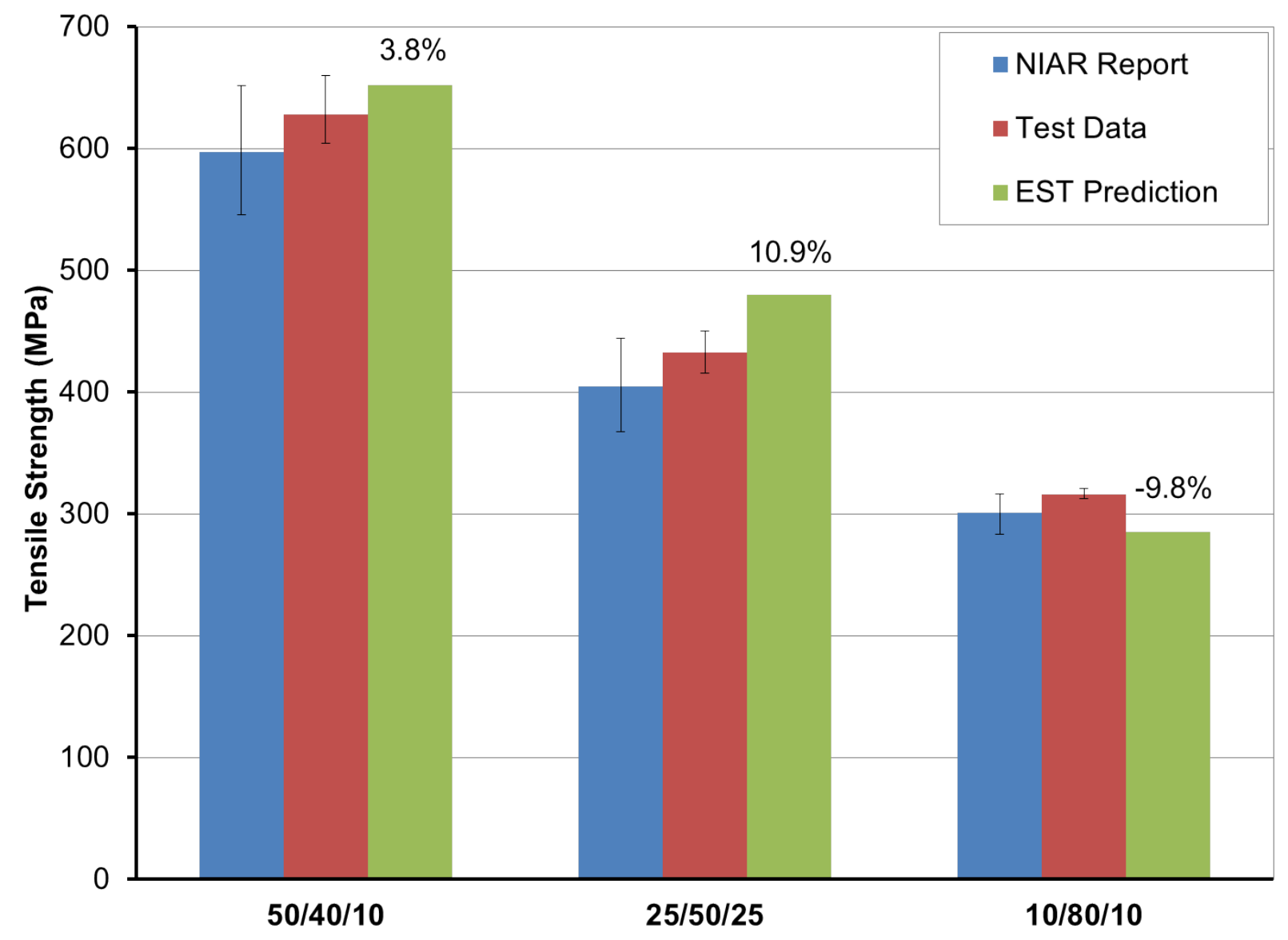

Figure 16. Open hole tension predictions compared with experiments 


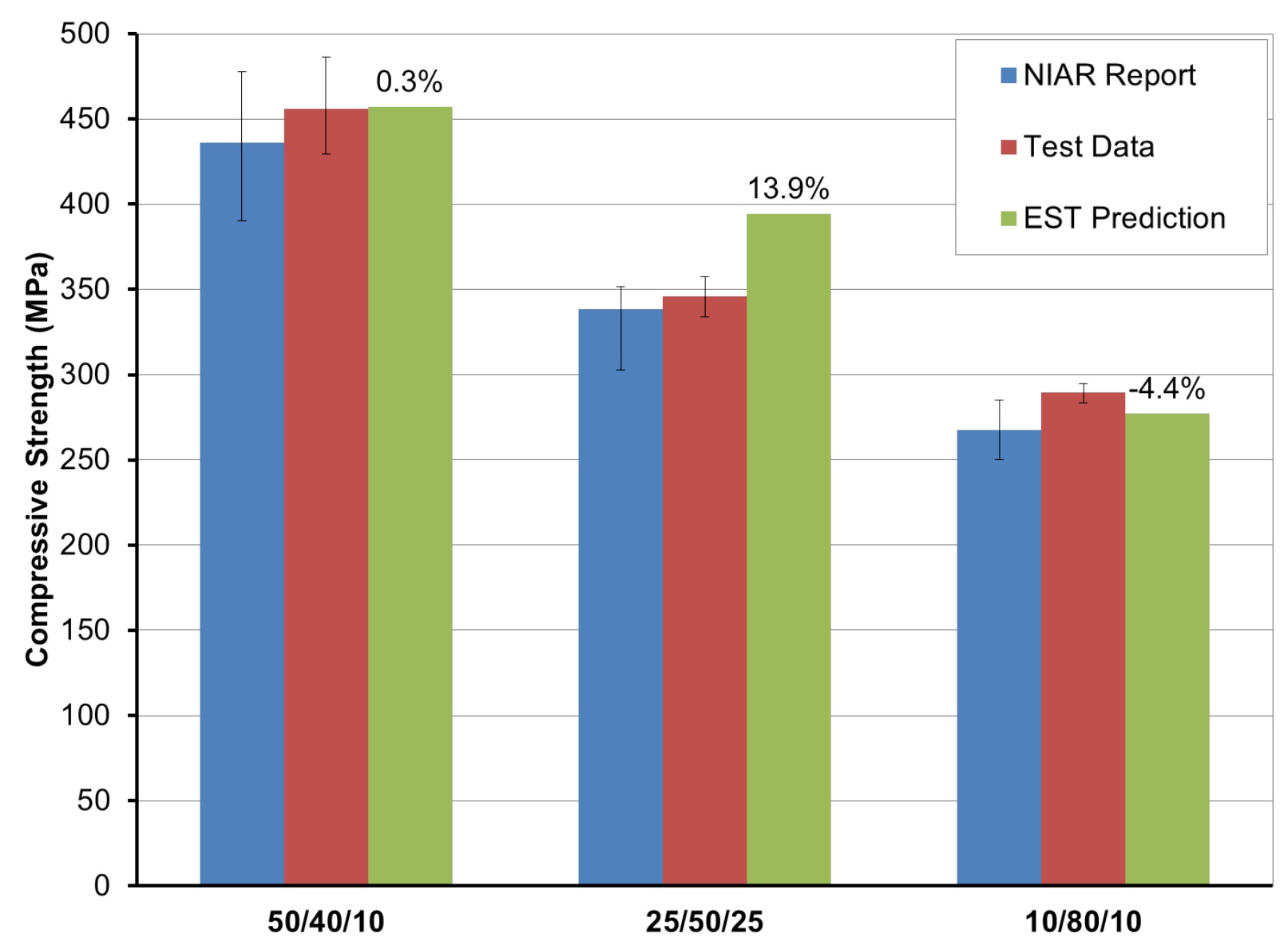

Figure 17. Open hole compression predictions compared with experiments 